\title{
The Relationship between Infection-Avoidance Tendencies and Exclusionary Attitudes toward Foreigners: A Panel Study of the COVID-19 Outbreak in Japan
}

\author{
Short title: COVID-19 and Exclusionary Attitudes
}

\author{
Mei Yamagata $^{1 *}$, Tsukasa Teraguchi ${ }^{1}$, and Asako Miura1 \\ ${ }^{1}$ Graduate School of Human Sciences, Osaka University, Suita, Japan \\ * Correspondence:
}

Mei Yamagata

yamagatamei7@gmail.com

\begin{abstract}
Amidst an outbreak of COVID-19 in January 2020, this study, which based on the behavioral immune system, focused on the preventive behaviors related to COVID-19 infection and Japanese people's exclusionary attitude toward foreigners, examining the time-series changes associated with the spread of the novel coronavirus in Japan, which was one of the first countries to confirm cases outside China. Also, we examined the effects of individual differences in infection-avoidance tendencies and the frequency of people's daily contact with foreigners. In late January, mid-February, and early March of 2020, this study conducted a panel survey 1,004 Japanese citizens aged 18 years or above living in Japan, and who had registered with the crowdsourcing service. The results indicated that as the spread of COVID-19 increased, tendencies toward infection-preventive
\end{abstract}




\section{COVID-19 and Exclusionary Attitudes}

behaviors increased, and exclusionary attitudes toward foreigners became stronger. Similarly, the avoidance response against unfamiliar people, including Japanese strangers increased. No relationship between the increased risk of infection and the Japanese respondents' exclusionary attitudes toward the Chinese but were more negative than that for other groups. However, it is difficult to conclude that all the reported exclusionary behaviors and attitudes were irrational or excessive false-positive errors. People with strong infection-avoidance tendencies engaged in more preventive actions, regardless of whether they were living under normal circumstances or under threat of infection, and they indicated strong exclusionary attitudes toward foreigners in general and the Chinese specifically under threat of infection. We observed a moderating that the higher the frequency of daily contact with foreigners, the weaker the exclusionary attitudes toward them. This study recorded the behavioral and psychological states of people in Japan during the 40 days preceding the WHO's 11 March 2020 declaration of the COVID-19 pandemic. The data collected in Japan, where the infection spread widely early on, will provide valuable insights for countries anticipating significant social changes.

Keywords: COVID-19, behavioral immune system, infection avoidance, exclusionary attitudes, preventive behavior 


\section{Introduction}

In January 2020, an outbreak of pneumonia infection (hereinafter referred to as COVID-19: coronavirus disease 2019), caused by a novel coronavirus (SARS-CoV-2), began in Wuhan, Hubei Province, China. Seemingly overnight, the number of infected and fatal cases reported worldwide grew exponentially. The seriousness of the outbreak became evident as the WHO declared a state of emergency (PHEIC: Public Health Emergency of International Concern) on 31 January 2020 (30 January UTC). With the situation changing rapidly and mixed information coming in from around the world, questions arose — among them, 'what kind of changes in behaviors and attitudes should humans adopt to avoid a sudden infection?' This study focused on the preventive behaviors related to COVID-19 infection and Japanese people's exclusionary attitude toward foreigners, examining the time-series changes associated with the spread of the novel coronavirus in Japan, which was one of the first countries (along with South Korea and Thailand) to confirm cases outside China (WHO, 2020). Also, we examined the effects of individual differences in infection-avoidance tendencies and the frequency of people's daily contact with foreigners.

This study recorded the behavioral and psychological states of people in Japan during the 40 days preceding the WHO's 11 March 2020 declaration of the COVID-19 pandemic, surveying 1,004 people in three waves as they lived through the early stages of the spread of the novel coronavirus and experienced rapid and unpredictable real-world changes. By then, the novel 


\section{COVID-19 and Exclusionary Attitudes}

coronavirus had begun to spread beyond Asia, with confirmed cases on every continent except Antarctica before the end of January (WHO, 2020). Japan confirmed its first case 15 January 2020 (WHO, 2020); by the time WHO declared the pandemic on 11 March, there were dozens of cases, some fatal. The data collected in Japan, where the infection spread widely early on, will provide valuable insights for countries anticipating significant social changes.

How do people behave when they are at increased risk of exposure to pathogens like COVID-19 for which there are no known cures or preventive vaccines? Historically, infections caused by deadly pathogens and parasites have severely threatened human survival (Ackerman et al., 2018, pp. 1-14; Curtis et al., 2011, pp. 389-401; Schaller and Park, 2011, pp. 99-103). In response, humans have developed a psychological system known as the behavioral immune system, 'a suite of psychological mechanisms that (a) detect cues connoting the presence of infectious pathogens in the immediate environment, (b) trigger disease-relevant emotional and cognitive responses, and thus (c) facilitate behavioral avoidance of pathogen infection' (Schaller and Park, 2011, pp. 99-103). These defense mechanisms are activated when signs of pathogens are detected, inducing an aversive emotion (Horberg et al., 2009, pp. 963-976; Masicampo et al., 2014, pp. 2135 2152) and driving cognitive modules that motivate humans to move away from perceived sources of infections (Schaller \& Park, 2011). In societies where the prevalence of pathogens or the risk of infection have been historically high, these anti-pathogen psychological tendencies are more 


\section{COVID-19 and Exclusionary Attitudes}

pronounced than in societies where their prevalence is low (Van Leeuwen et al, 2012, pp. 429-437).

The behavioral immune system is considered an adaptation aimed at community maintenance, and it drives humans to take steps to prevent infection and avoid pathogens, such as cleaning themselves and isolating infected people (Haidt, 2012, pp. 150-179).

Because the behavioral immune system drives pathogen-avoidance through cue-based inferences, it often results in two errors: false-positive errors that presume the presence of pathogens despite their absence and false-negative errors that presume the absence of pathogens despite their presence. Of the two, the latter (the mistaken presumption of safety) is the more grave since it can lead to the spread of infection, but the former (the mistaken presumption of danger) is extremely common, having evolved to 'minimize the likelihood of (potentially fatal) false-negative errors' (Schaller and Park, 2011, pp. 99-103).

The frequency of false-positive errors means that people often assume others to be infected when they are not; people are especially likely to associate the presence of pathogens with strangers and those whose behaviors in the areas associated with disease transmission (e.g. food preparation, personal hygiene, etc.) differ from theirs (Faulkner et al., 2004, pp. 333-353). There is some biological basis for these adaptive behaviors for avoiding infection: coming into contact with outgroup members may increase the chance of infection from pathogens for which in-group members have not yet developed immunity (Diamond, 1999). However, it is often based on fear of the 


\section{COVID-19 and Exclusionary Attitudes}

unknown, prejudice, and xenophobic reactions toward those seen as outsiders who are perceived as violating a community's infection control norms and thus pose a threat of infection (Faulkner et al., 2004, pp. 333-353). Not surprisingly, now that a high risk of COVID-19 infection has activated so many people's behavioral immune systems, the prevalence of false-positive errors has led to the widespread adoption of avoidance behaviors that include shunning contact with foreigners.

As adaptive actions by the behavioral immune system, preventive actions to protect a community can lead to exclusionary attitudes — avoiding people from other communities and outgroups that have (or are thought to have) more infected members. Previous studies have shown a high prevalence of distrust and discrimination against foreigners, especially unfamiliar ones (Brenner and Inbar, 2014, pp. 27-38; Faulkner et al., 2004, pp. 333-353) and people who are somehow different, such as those who are obese (Brenner and Inbar, 2014, pp. 27-38; Masicampo et al., 2014, pp. 2135-2152; Park and Isherwood, 2011, pp. 391-394; Park et al, 2007, pp. 410-414). It has also been shown that presenting images of threats such as plagues and infections reduces participants' positive attitudes toward unfamiliar foreigners, regardless of whether they had been associated with infections (Faulkner et al., 2004, pp. 333-353). If we apply these findings to Japan and the spread of COVID-19 infection, we would expect people to reject not only of those from China - the center of the outbreak — but other foreigners, too. 


\section{COVID-19 and Exclusionary Attitudes}

There are several reasons why the behavioral immune system may lead people to extend their exclusionary attitudes to include all foreigners. People's initial responses to the increased risk of a particular infection, such as more frequent and thorough handwashing and isolating infected patients, (Haidt, 2012, pp. 150-179). However, these are essential temporary emergency measures to mitigate a specific threat. These actions are not focused on long-term safety and prevention. One strategy to ensure long-term safety from pathogens is to eliminate opportunities for people to come into contact with (a) people who have been infected and (b) those from outside the infection-free community who are likely to carry new pathogens. Thus, the instinctive reaction is to cut off contact with foreigners. This process of excessive exclusion leads to widespread false-positive errors from the hyperactivation of the behavioral immune system.

Also, the worldwide pandemic of COVID-19 is reminiscent of the 2003 outbreak of the severe acute respiratory syndrome coronavirus (SARS-CoV or SARS-CoV-1). Lee-Baggley et al. (2004, pp. 9-23) examined the psychological effects of SARS in residents of Canada, the United States, and China (of which 19\% lived in a SARS-affected area), starting a three-month online survey on 8 June 2003 after the spread of SARS was confirmed. The study showed that regardless of respondents' gender, educational background, or residence in a SARS-affected area, those who felt threatened were more likely people were to use wishful thinking and support-seeking as coping strategies and to engage in specific health-related behaviors, such as avoiding public places (e.g. 


\section{COVID-19 and Exclusionary Attitudes}

restaurants, public transportation), avoiding people they suspected to be carriers of the pathogen (e.g. visitors from a known source region of SARS, strangers without masks), and changing their regimens (e.g. wearing masks, frequent handwashing, resting).

Both SARS and its new variant COVID-19 are threats caused by novel coronavirusesnew viral infections not previously experienced by humans anywhere in the world at the time of their outbreaks. Therefore, the effects of COVID-19 examined in our study are expected to be similar to those found in studies on SARS. Thus, we developed the following hypothesis:

H1: As COVID-19 spreads in Japan, infection-prevention actions will increase and exclusionary attitudes toward the Chinese and other foreigners will grow stronger.

In this study, we assumed individual differences in infection-avoidance tendencies as a variable that modified the time-series change in exclusionary attitudes with the spread ofCOVID-19 infection. In a previous study examining the relationship between infection-avoidance and individual difference variables, individuals who were prone to be averse to physical and mental contaminations, including infection from pathogens, tended to have negative attitudes toward foreigners, and this mechanism is thought to be based on the behavioral immune system (Brenner and Inbar, 2014, pp. 27-38). Evolutionally, such individuals are less likely to take pathogens into the body than others (Haidt, 2012, pp. 150-179) and more likely to adopt routine preventive actions to keep themselves clean because disgust is an evolved psychological system for protecting 


\section{COVID-19 and Exclusionary Attitudes}

organisms from infection through disease-avoidant behavior (Curtis et al., 2011, pp. 389-401). In addition, individuals who perceive the threat of diseases to be high or have heightened recognition of their vulnerability to diseases are more likely to exhibit pathogen-avoidance behaviors and attitudes when faced with a high risk of infection (Goh, 2020; Faulkner et al., 2004, pp. 333-353). It has been shown that such behaviors and attitudes are mediated by concerns about pathogens that have been acquired evolutionarily (Park and Isherwood, 2011, pp. 391-394). These findings show that those who have strong infection-avoidance tendencies engage in various infection-preventive activities on a daily basis and have strong exclusionary attitudes toward out-groups, especially foreigners. Thus, sudden threats of infection such as COVID-19 are unlikely to cause radical changes in their behaviors and attitudes. In contrast, those who have weak infection-avoidance tendencies are more likely to make rapid, radical changes that increase their infection-avoidance behaviors in response to sudden threats. Thus, we developed three additional hypotheses:

H2: People who have strong infection-avoidance tendencies will take more preventive actions daily and have strong exclusionary attitudes.

H3a: People who have strong infection-avoidance tendencies will not change their infectionpreventive actions or exclusionary attitudes, even as the COVID-19 infection spreads. 


\section{COVID-19 and Exclusionary Attitudes}

H3b: People who have weak infection-avoidance tendencies will increase their infectionpreventive actions and develop stronger exclusionary attitudes as the COVID-19 infection spreads.

The frequency of daily contact with foreigners may also modify the time-series changes in exclusionary attitudes associated with the spread of COVID-19 infection. Faulkner et al. (2004, pp. 333-353) examined how people's acceptance of the Canadian government's immigration policies were affected by viewing images related to plagues and infections. When the images were not presented, participants exhibited no difference in their acceptance of immigrants, regardless of their countries of origin. In contrast, when the images were presented, participants exhibited lower acceptance of immigrants from unfamiliar countries compared to immigrants from familiar countries. Importantly, this indicates that familiarity is associated with exclusionary attitudes. Furthermore, it has been shown that multicultural experience and knowledge reduces stereotypes about and prejudices against out-groups (minority groups) (Tadmor et al., 2012, pp. 750-772). This suggests that daily familiarity or frequent contact with foreigners may modify the changes in exclusionary attitudes, and this led us to our final hypothesis:

H4: Exclusionary attitudes will not increase in people with a high frequency of daily contact with foreigners, even when the COVID-19 infection spreads. 


\section{Materials and methods}

In this study, we examined time-series changes in infection-avoidance behavior in Japan using a panel survey to be conducted in waves throughout 2020. This paper covers wave one (31 January to 1 February), two (18-20 February), and three (4-6 March), but the survey remains ongoing.

\subsection{Ethics statement}

The study was approved by the Osaka University Graduate School of Human Sciences Research Ethics Committee, Behavioral Division (HB019-099).

\subsection{Participants}

The subjects of this study were Japanese citizens aged 18 years or above who lived in Japan and had registered with the crowdsourcing service Cloudworks Co., Ltd. We obtained their written consent to participate in this study. The first wave of the survey had 1,248 participants (424 men, average age 37.03 years \pm 9.53 ). Of these, 1,200 traceable respondents were asked to participate in the second wave of the survey, and valid responses were obtained from 1,076 respondents (371 men, average age 37.79 years \pm 9.43), a response rate of $89.7 \%$. Valid respondents in the second wave were asked to participate in the third wave, and valid responses were obtained from 1,004 respondents ( 350 men, average age 38.19 years \pm 9.34 ), a response rate 


\section{COVID-19 and Exclusionary Attitudes}

of $93.3 \%$. We used a Directed Questions Scale (Miura \& Kobayashi, 2019) to detect inattentive respondents, and cases where two consecutive questions were not answered correctly were excluded from the analysis.

\subsection{First wave of the survey 1}

Japan was in the 'warning phase for infection' from COVID-19 at the end of January 2020, when the first wave of the survey was conducted. On 27 January, the Ministry of Health, Labor and Welfare recognized COVID-19 as a designated infectious disease, and more than ten cases of infection in Japanese patients had been confirmed at the time.

\subsubsection{Questionnaire items}

We examined items related to the COVID-19 outbreak: (1) the degree of interest in COVID-19; (2) whether infection-preventive actions were taken before and after the outbreak (11 items, including wearing a mask and refraining from leaving home); and (3) four items of risk perception, with the two dimensions of 'dread': 'will result in death and cannot be undone' and 'unknown: we may be affected without realizing it and cannot tell what type of effect this will have'; these were drawn from studies by Komori et al. (2019) and Slovic (1987, pp. 280-285)) of events with the risk of death (e.g. COVID-19, nuclear accidents, AIDS, etc.).

\footnotetext{
${ }^{1}$ Questionnaire preview: https://bit.ly/38Wd8P8
} 


\section{COVID-19 and Exclusionary Attitudes}

The degree of infection-avoidance was determined by five items of 'infection avoidance'

from the purity orientation/pollution-avoidance scale the cleanliness-preference/dirtinessavoidance subscale (Kitamura and Matsuo, 2019, p. 20), such as 'I feel uncomfortable if I do not wash my hands before eating': $\alpha=.71)$. We also determined the frequency of daily contact with foreigners, asking those who had contact about their number of Chinese and other foreign friends and acquaintances.

We used two measures of exclusionary attitudes: (1) four items on acceptance attitudes toward foreigners in general and Chinese people specifically (i.e., 'It is good that many foreigners (Chinese people) come to Japan for sightseeing' and 'It is good that many foreigners (Chinese people) come to Japan to work'); and (2) one item on foreigner-avoidance attitudes ('Only Japanese people should live in Japan') based on Mifune and Yokota (2018, pp. 94-101). Finally, we included four items related to impressions of foreigners in general, Chinese people, Americans, and Japanese people (the choices were 'irritating', 'frightening', 'reliable', and 'interesting'). We also gathered demographic data from the respondents (i.e. age, gender, and prefecture where they lived).

\subsection{Second wave of the survey ${ }^{2}$}

\footnotetext{
${ }^{2}$ Questionnaire preview: https://bit.ly/3deXsIp
} 


\section{COVID-19 and Exclusionary Attitudes}

\subsubsection{Changes in the situation after the first wave}

The COVID-19 situation in Japan worsened drastically after the first wave of the survey.

The first cases of death in Japan caused by the novel coronavirus had been announced, and new cases of infection were being confirmed throughout the country. Also, the number of cases in which the infection route was not clear began to increase, and new cases on the cruise ship Diamond Princess were being reported daily. The number of infected people worldwide had also increased significantly. In response to the rapid spread of COVID-19, throughout Japan, many large-scale events expecting sizeable crowds were cancelled. By February 16, the Japanese government had recognized the situation as being the early stage of what would be widespread domestic outbreak — the stage immediately before a pandemic — and on the following day, the government established guidelines relating to the COVID-19 infection to address the imminent pandemic.

Given these changes, we could assume that people living in Japan would believe themselves to be at a greater risk being infected with COVID-19 than they had during the first wave of the survey, and they had a more informed understanding of the dangers of the disease. It was also likely that they had an increased awareness that cleanliness alone was not sufficient to prevent the spread of infection and that the risk of infection was high when people in their community tested positive for the pathogens. In such situations, people often seek to reduce the 


\section{COVID-19 and Exclusionary Attitudes}

size of their circle of contacts for security. Thus, we considered that as the risk of infection increased, there would be a concomitant increase in the likelihood that people would view not only foreigners but any strangers as out-groups and show stronger exclusionary attitudes toward unfamiliar people. To examine this possibility exploratively, we added 'close friends' and 'people you see when you go out' to the impression evaluation.

\subsubsection{Questionnaire items}

The items we added in the second wave of the survey related to the following: (1) an estimation of the probability of COVID-19 infection (\%) and its likely source of infection (openended question); (2) the degree to which respondents used various means to collect COVID-19 information; (3) perceptions of 'influenza' risk; and (4) contact data on 'close friends' and 'people you see when you go out' (i.e. unfamiliar people). Since the respondents were a subset of those participating in the first-wave survey, we removed the items on whether the respondents had engaged in infection-preventive behaviors before the pandemic, their frequency of daily contact with foreigners, and demographic variables.

\subsection{Third wave of the survey ${ }^{3}$}

\footnotetext{
${ }^{3}$ Questionnaire preview: http://u0u1.net/jcVU
} 


\section{COVID-19 and Exclusionary Attitudes}

\subsubsection{Changes in the situation after the second wave}

The number of infected people in Japan further increased after the second wave. On 23

February, the government had announced that the country was in a 'transitional phase' of infection spread. On 25 February, the Infectious Disease Control Headquarters began implementing formal measures that caused dramatic changes in the lives of people living in Japan. Therefore, for the third wave of the survey, we added items that focused on respondents' approval of government measures and how those measured had affected their lives.

\subsubsection{Questionnaire items}

The items we added in the third wave of the survey related to the following: (1) the presence or absence of infected individuals in the respondents' immediate vicinity, and if present, their relationship with the individual(s) (multiple choice question); (2) speculations on the likely infection route (multiple choice question); (3) attitudes toward the new government policies and their impact on the respondents' lives; (4) political ideology; and (5) level of scientific knowledge (five quiz-type questions, two of which were related to pathogen infection).

\section{Results}




\section{COVID-19 and Exclusionary Attitudes}

Table 1 shows the basic statistics for the individual items in each wave. Below, we describe the notable attributes in each category of items and the hypothesis testing and exploratory analyses.

\subsubsection{Items related to the COVID-19 outbreak}

Interest in COVID-19 has increased since the first wave of the survey, and the result of a one-way ANOVA (Wave 1 vs. Wave 2 vs. Wave 3) showed that the effect size over time has been small $\left(\eta^{2}=.01\right)$. The perceived possibility of infection increased from the second wave to the third wave, but the result of a t-test (Wave 2 vs. Wave 3) showed that the effect size over time was not very large $\left(\eta^{2}=.14\right)$. For all three waves, risk perception was the highest for COVID-19 from among other infectious diseases, influenza, and AIDS.

The respondents reported that the number of infection-preventive actions they took before the outbreak increased after the outbreak, but the movement was not uniform; for example, there was an increase in the number of respondents who began engaging in infection-preventive measures, but a decrease in the number of respondents who decided to 'sleep enough' - and, contrary to expectations, to 'refrain from going to sightseeing spots frequently visited by the Chinese or other foreigners'.

\subsubsection{Infection-avoidance tendencies}

The infection-avoidance score was already markedly high at the time of the first wave of the survey, and the result of a one-way ANOVA (Wave 1 vs. Wave 2 vs. Wave 3 ) showed that the 
effect size over time was small $\left(\eta^{2}=.0013\right)$. According to Kitamura (unpublished data), the average score in a survey conducted in Japan in 2019 of both university students and the general public was approximately 3.6. Therefore, we can safely infer that the increase in the infectionavoidance score in our study was likely due to the COVID-19 outbreak.

\subsubsection{Frequency of daily contact with foreigners}

Approximately two-thirds of the responses to the question on the frequency of daily contact with foreigners indicated 'none', and $92.6 \%$ and $78.3 \%$ of the respondents did not have any Chinese or other foreign acquaintances, respectively.

\subsubsection{Exclusionary attitudes}

The average score of acceptance attitudes toward foreigners in general and the Chinese specifically tended decreased over time, but the result of a one-way ANOVA(Wave 1 vs. Wave 2 vs. Wave 3) showed that the effect size over time was small (Foreigners in general: $\eta^{2}=.0019$; Chinese: $\left.\eta^{2}=.0001\right)$. A comparison of foreigners in general and the Chinese specifically showed that the acceptance attitude toward the Chinese was consistently low, as evidenced by a t-test $\left(\eta^{2}=.41\right)$. In addition, the result of a one-way ANOVA (Wave 1 vs. Wave 2 vs. Wave 3 ) showed that although the average score of avoidance attitudes toward foreigners in general increased over time, the effect size was small $\left(\eta^{2}=.0005\right)$. 


\section{COVID-19 and Exclusionary Attitudes}

For all three waves, the average score of the negative impression of the Chinese was higher than that for other groups, and the average score of the positive impression of the Chinese was lower than for other groups. The results of a one-way ANOVA (Foreigners in general vs. Chinese vs. Americans vs. Japanese vs. Friends vs. Unfamiliar) showed that the average score of the negative impressions ('irritating' and 'frightening') of the Chinese was higher than for the other groups (main effect: $\eta^{2}=.20$; Foreigners in general: $g=.68[.61, .74]$; Americans: $g=.78[.72, .85]$; Japanese: $g=.72[.65, .78]$; Friends: $g=1.63[1.56,1.70]$; and Unfamiliar: $g=.86[.79, .92]$. The average score of the positive impressions ('reliable' and 'interesting') of the Chinese was lower than for the other groups (main effect: $\eta^{2}=.37$; Foreigners in general: $g=-.75[-.81,-.69]$; Americans: $g=-.86$ [-.92, -.80]; Japanese: $g=-1.16[-1.22,-1.09]$; Friends: $g=-2.17[-2.24,-2.09]$; and Unfamiliar: $g=-.06[-.12, .00]$.

\subsection{Hypothesis testing}

Next, we tested the hypotheses using the data from the 1,004 respondents who participated in all three waves of the survey.

\subsubsection{Number of infection-preventive actions}

To test from Hypotheses 1-3 on the number of infection-preventive actions, we examined the explanatory variables of sex $(0=$ female $)$, age, interest in COVID-19, infection avoidance at 


\section{COVID-19 and Exclusionary Attitudes}

the time of the first wave, wave points, and the interaction between infection-avoidance tendencies and wave points; to do this, we used a generalized linear mixed model. Respondents were entered as random effects, and a Poisson distribution was assumed because the number of infectionpreventive actions was discrete values. The results are shown in Table 2.

The results supported Hypothesis 1, which posited that over time, infection-preventive behaviors would increase with the spread of COVID-19 infection in Japan. However, we observed no interaction effect between the passage of time and infection-avoidance tendencies; thus, Hypothesis 3 was not supported. To test Hypothesis 2, which posited that people with strong infection-avoidance tendencies would take more preventive actions daily and have strong exclusionary attitudes, we used a generalized linear model with gender $(0=$ female $)$, age, interest in COVID-19, and infection-avoidance tendencies at the first wave as explanatory variables (see Table 3). The results showed that people with a stronger infection-avoidance tendency routinely engaged in infection-preventive behaviors even before the outbreak, thus supporting Hypothesis 2.

\subsubsection{Exclusionary attitudes}

Table 4 shows the results of our testing of Hypotheses 1-4 on the three dependent variables of exclusionary attitudes. To test the respondents' foreigner-avoidance and acceptance attitudes toward foreigners in general and Chinese people specifically, we examined the explanatory variables of sex $(0=$ female $)$, age, interest in COVID-19, infection avoidance 


\section{COVID-19 and Exclusionary Attitudes}

tendencies at the time of the first wave, frequency of daily contact with foreigners, wave points, the interaction between infection-avoidance tendencies and wave points, and the interaction between the frequency of daily contact with foreigners and wave points, using a linear mixed model. The respondents were entered as random effects.

The results relating to the acceptance attitudes toward foreigners in general indicated a negative effect of time points of the third wave and infection-avoidance tendencies, thus supporting Hypotheses 1 and 2. However, we did not observe any effects from the interaction between infection-avoidance tendencies and the passage of time or the interaction between the frequency of daily contact with foreigners and the passage of time; thus, Hypotheses 3 and 4 were not supported.

The results relating to the acceptance attitudes toward the Chinese indicated no effect of the passage of time; thus, Hypothesis 1 was not supported. We found a negative effect from infection-avoidance tendencies, which supported Hypothesis 2. However, we did not observe any effects from the interaction between infection-avoidance tendencies and the passage of time or the interaction between the frequency of daily contact with foreigners and the passage of time; thus, Hypotheses 3 and 4 were not supported.

The results relating to the foreigner-avoidance attitude indicated a negative effect of time points of third wave and infection-avoidance tendencies, thus supporting Hypotheses 1 and 2. 


\section{COVID-19 and Exclusionary Attitudes}

However, we did not observe any effects from the interaction between infection-avoidance tendencies and the passage of time or the interaction between the frequency of daily contact with foreigners and the passage of time; thus, Hypotheses 3 and 4 were not supported.

In summary, acceptance attitudes toward foreigners grew more negative over time or with a higher infection-avoidance tendency. The frequency of daily contact with foreigners did not moderate these relationships. Acceptance attitudes toward the Chinese were not significantly affected over time but were more negative during the first wave.

\subsection{Exploratory analysis}

For the exploratory investigation of exclusionary attitudes toward unfamiliar people, including citizens of their own country, we analyzed the respondents' negative and positive impressions of unfamiliar people (those objective variables were examined only in the second and third waves) using a linear mixed model with the respondents entered as random effects. The variables entered as explanatory variables are shown in Table 5. The results showed that only negative impressions were affected by the passage of time and that impressions of unfamiliar people became negative over time.

\subsection{Descriptive statistics on other variables}


The basic statistics of each wave for other variables are shown in the Supplementary Material. Space limitations preclude a full discussion of all the characteristic results. However, one notable result was this: approval of government measures was neutral on average, with few respondents showing a strong attitude, and their correlation with ideology was weak at 0.15 . The consequence reported as having the most substantial negative impact on respondents' lives was the increased difficulty in acquiring daily necessities.

\section{Discussion}

In this study, we focused on the respondents' preventive behaviors against COVID-19 infection and their exclusionary attitude toward foreigners, examining the time-series changes associated with the spread of COVID-19 infection in Japan based on the behavioral immune system. Also, we examined the effects of individual differences in the infection-avoidance tendencies and the frequency of daily contact with foreigners.

\subsection{Effect of the threat of infection risk over time}

Hypothesis 1, which examined changes in behavior over time, was supported, except with respect to exclusionary attitudes toward Chinese people. As the spread of COVID-19 increased, tendencies toward infection-preventive behaviors increased, and exclusionary attitudes toward 


\section{COVID-19 and Exclusionary Attitudes}

foreigners became stronger. Each wave of the survey showed an increase in the number of infection-preventive actions compared to before the COVID-19 outbreak, but the movement was not uniform; from high to low, the number sequence was first wave to third wave to second wave to prior to outbreak. Although the reason for this is not clear, we theorized that rising fears of infection might have provoked the temporary implementation of comprehensive preventive behaviors, which in turn may have led to the subsequent selection of more appropriate behaviors.

Our finding that exclusionary attitudes toward foreigners increased with the spread of COVID-19 is consistent with the findings from previous studies examining exclusionary attitudes toward out-group members under the threat of infection risk (Faulkner et al., 2004, pp. 333-353; Goh, 2020; Lee-Baggley et al., 2004, pp. 9-23; Park et al 2007, pp. 410-414). Previous studies have mainly examined threats of infection risk by experimental manipulations at a single time point (Faulkner et al., 2004, pp. 333-353; Park et al 2007). In contrast, our study examined the effects of the passage of time, which revealed changes in behaviors and attitudes caused by the increasing threat of infection. However, it should be noted that our study has been dealing with a real event in which dramatic changes are ongoing (as is this study) and have occurred rapidly. In early March, a pandemic was declared, and this sent the clear message to the Japanese people that anyone from any location— not just people from China — might be carrying COVID-19 pathogens. 


\section{COVID-19 and Exclusionary Attitudes}

Thus, it is difficult to conclude that all the reported exclusionary behaviors and attitudes were irrational or excessive false-positive errors.

Notably, we found no relationship between the increased risk of infection and the Japanese respondents' exclusionary attitudes toward the Chinese. The reason for this may be that from the outset of the study, the source and center of the novel coronavirus infection was known to be China. In addition, at the time of the first wave of the survey, people were already well aware of the increasing risk of infection, indicating that the behavioral immune system had already been activated. Under the threat of infection, the respondents' exclusionary attitudes toward the Chinese related to infection might be seen as a type of rational reaction.

Similarly, just as we saw increasing exclusionary attitudes and negative impressions of unfamiliar people (not just foreigners but strangers, too), we saw an increase in the preventive behavior of 'refrain from going out'; the most frequently cited expected route of infection was 'the unspecified number of unfamiliar people'. Faulkner et al. (2004, pp. 333-353) found that the degree of support for the immigrant acceptance policy under the threat of infection varies, with greater acceptance of people from foreign but familiar countries, and this may also apply to the avoidance response against unfamiliar people, including Japanese strangers.

\subsection{Effects of individual differences in infection avoidance tendencies}




\section{COVID-19 and Exclusionary Attitudes}

Hypothesis 2, which tested individual differences in people's tendencies to avoid infections, was supported. People with strong infection-avoidance tendencies engaged in more preventive actions, regardless of whether they were living under normal circumstances or under threat of infection, and they indicated strong exclusionary attitudes toward foreigners in general and the Chinese specifically under threat of infection. This result is consistent with the findings of previous studies (Brenner and Inbar, 2014, pp. 27-38; Goh, 2020; Faulkner et al., 2004, pp. 333353; Park and Isherwood, 2011, pp. 391-394) that examined the relationship between infectionavoidance behaviors and attitudes and individual differences in evolutionarily acquired concerns about pathogens.

\subsection{Effects of passage of time and individual differences in infection-avoidance tendencies} and frequency of daily contact with foreigners

Interactions between the passage of time and individual differences in infection-avoidance tendencies and the frequency of daily contact with foreigners were not significant; thus, Hypotheses 3 and 4 were not supported. Since this study was conducted after the COVID-19 outbreak became widely known, it was not possible to determine the respondents normal preCOVID-19 attitudes of living without the threat of this particular infection. Given that the effect size over time was small, our results suggest that a specific reaction might have already happened, 


\section{COVID-19 and Exclusionary Attitudes}

before the start of the study, and that there was no abrupt change from the normal state. However, we observed a moderating: the higher the frequency of daily contact with foreigners, the weaker the exclusionary attitudes toward them. This is consistent with findings that people have low exclusionary attitudes toward foreigners from familiar countries (Faulkner et al., 2004, pp. 333353) and that multicultural experience reduces prejudiced attitudes (Tadmor et al., 2012, pp. 750772).

\subsection{Limitations and future directions}

As mentioned above, the concerns of the Japanese people were considered to have increased significantly even by the time of the first wave of the survey, and we had no reliable data on their pre-pandemic attitudes that can be used as a control. In the future, we hope to resolve this limitation by obtaining relevant data from previous studies and tracking data after the end of the COVID-19 pandemic. Given the low dropout rate of the panel and the need to answer the same questions in a very short time, it is possible that social desirability and demand characteristics strongly influenced the responses. In the future, we would like to explore this by conducting surveys with new respondents in parallel with the current panel survey.

Since the COVID-19 infection has been rapidly spreading throughout Europe and the United States and is no longer a regional disease ravaging only East Asia, there is a growing need 


\section{COVID-19 and Exclusionary Attitudes}

for international comparisons of the behavioral and psychological states of the affected populations.

It is unlikely that our findings describe phenomena unique to Japan. The results of this research, which assumed the widespread activation of the evolutionary psychological infection-defense system, may help clarify people's responses to this global pandemic. For example, knowing the foundations that underlie infection-avoidance, including concepts of morality (Haidt and Graham, 2007, pp. 98-116; Haidt and Joseph, 2007, pp. 367-391) and cultural differences, may make it possible to predict changes in attitudes and behaviors beyond other the exclusionary attitudes toward foreigners by examining the secondary effects of avoidance behaviors on other bodily/spiritual pollution (e.g. respect for religion and faith observances).

We hope that the large-scale accumulation of COVID-19 research will contribute to solving social problems, including addressing the exclusionary attitudes toward foreigners noted in this study, not only in Japan but around the world.

\section{Acknowledgments}

We wish to thank Dr. Hideya Kitamura (Toyo University) for allowing us to use the purity orientation/pollution-avoidance scale and offering useful comments on this survey and Editage for translating, editing, and reviewing this manuscript for its English language.

\section{Author Contributions}




\section{COVID-19 and Exclusionary Attitudes}

MY conceived of and co-designed the study; collected and organized the data; conducted the data analysis; and drafted the manuscript. TT contributed to the data analysis and provided the critical comments on drafts of the manuscript. AM co-designed the study; collected, organized, and supervised the data; and provided the critical comments on drafts of the manuscript. All authors read and approved the final manuscript.

\section{$7 \quad$ Conflict of Interest}

The authors declare that the research was conducted in the absence of any commercial or financial relationships that could be construed as a potential conflict of interest.

\section{Data Availability Statement}

This study is in the process of conducting a follow-up panel survey. We will perform another analysis that includes the data reported here. Therefore, the data cannot be published at this time.

\section{Supplementary Material}

The Supplementary Material for this article can be found online at https://osf.io/4hjat/

\section{Reference}




\section{COVID-19 and Exclusionary Attitudes}

Ackerman, J. M., Hill, S. E., \& Murray, D. R. (2018). The behavioral immune system: Current concerns and future directions. Soc Personal Psychol Compass. 12, e12371, 1-14. https://doi.org/10.1111/spc3.12371

Brenner, C. J., \& Inbar, Y. (2014). Disgust sensitivity predicts political ideology and policy attitudes in the Netherlands. Eur. J. Soc. Psychol. 45, 27-38. https://doi.org/10.1002/ejsp.2072

Curtis, V., de Barra, M., \& Aunger, R. (2011). Disgust as an adaptive system for disease avoidance behavior. Philos. Trans. R. Soc. B 366, 389-401. https://doi.org/10.1098/rstb.2011.0002

Diamond, J. (1999). Guns, germs, and steel. New York: Norton.

Faulkner, J., Schaller, M., Park, J. H., \& Duncan, L. A. (2004). Evolved disease-avoidance mechanisms and contemporary xenophobic attitudes. Group Process. Intergr. Relat. 7, 333353. https:/doi.org/ $10.1177 / 1368430204046142$

Goh, J. X. (2020). Perceived vulnerability to disease predicts restrictive policy supports in response to the 2019-nCoV outbreak. PsyArXiv Preprints. https://doi.org/10.31234/osf.io/52bw4

Haidt, J. (2012). The righteous mind: Why good people are divided by politics and religion. New York: Pantheon.

Haidt, J., \& Graham, J. (2007). When morality opposes justice: Conservatives have moral intuitions that liberals may not recognize. Soc. Justice. 20, 98-116. https://doi.org/10.1007/s11211-007-0034-z

Haidt, J., \& Joseph, C. (2007). "The moral mind: How 5 sets of innate intuitions guide the development of many culture-specific virtues, and perhaps even modules," in The Innate Mind, eds., P. Carruthers, S. Laurence, and S. Stich (New York: Oxford University Press), Vol. 3, pp. 367-391.

Horberg, E. J., Oveis, C., Keltner, D., \& Cohen, A. B. (2009). Disgust and the moralization of purity. J. Pers. Soc. Psychol. 97, 963-976. https://doi.org/10.1037/a0017423 


\section{COVID-19 and Exclusionary Attitudes}

Kitamura, H. \& Matsuo, A. (2019). Development and validation of the Purity Orientation/Pollution-Avoidance Scale. Presented at the $27^{\text {th }}$ Meeting of Japan Society for Research on Emotions, Nagoya, Japan. (In Japanese, translated by Kitamura, H.)

Komori, M., Miura, A., Matsumura, N., Hiraishi, K., \& Maeda, K. (2019). Spread of risk information through microblogs: Twitter users with more mutual connections relay news that is more dreadful. Jpn. Psychol. Res. (online first) https://doi.org/10.1111/jpr.12272

Lee-Baggley, D., DeLongis, A., Voorhoeave, P., \& Greenglass, E. (2004). Coping with the threat of severe acute respiratory syndrome: Role of threat appraisals and coping responses in health behaviors. Asian J. Soc. Psychol. 7, 9-23. https://doi.org/10.1111/j.1467-839X.2004.00131.x

Masicampo, E. J., Barth, M., \& Ambady, N. (2014). Group-based discrimination in judgments of moral purity-related behaviors: Experimental and archival evidence. J. Exp. Psychol. Gen. 143, 2135-2152. https://doi.org/10.1037/a0037831

Mifune, N., \& Yokota, K. (2018). The external validity of the relationship between social dominance orientation and political or discriminatory attitudes toward foreigners using a Japanese sample. Jpn, J. Soc. Psychol. 34, 94-101. (In Japanese, with English abstract) https://doi.org/10.14966/jssp.1725

Miura, A., \& Kobayashi, T. (2019). Survey satisficing biases the estimation of moderation effects. Jpn. Psychol. Res. 61, 204-210. https://doi.org/10.1111/jpr.12223

Park, J. H., Schaller, M., \& Crandall, C. S. (2007). Pathogen-avoidance mechanisms and the stigmatization of obese people. Evol. Hum. Behav. 28, 410-414. https://doi.org/10.1016/j.evolhumbehav.2007.05.008

Park, J. H., \& Isherwood, E. (2011). Effects of concerns about pathogens on conservatism and antifat prejudice: Are they mediated by moral intuitions? J. Soc. Psychol. 151, 391-394. https://doi.org/10.1080/00224545.2010.481692 


\section{COVID-19 and Exclusionary Attitudes}

Schaller, M., \& Park, J. H. (2011). The behavioral immune system (and why it matters). Curr. Dir. Psychol. Sci. 20, 99-103. https://doi.org/10.1177/0963721411402596

Slovic, P. (1987). Perception of risk. Science, 236, 280-285. https://doi.org/10.1126/science.3563507

Tadmor, C. T., Hong, Y.-Y., Chao, M. M., Wiruchnipawan, F., \& Wang, W. (2012). Multicultural experiences reduce intergroup bias through epistemic unfreezing. J. Pers. Soc. Psychol. 103, 750-772. https://doi.org/10.1037/a0029719

Van Leeuwen, F., Park, J. H., Koenig, B. L., \& Graham, J. (2012). Regional variation in pathogen prevalence predicts endorsement of group-focused moral concerns. Evol. Hum. Behav. 33, 429-437. https://doi.org/10.1016/j.evolhumbehav.2011.12.005

World Health Organization. (2020). Novel coronavirus (2019nCoV) situation report 1: 21 January 2020. Geneva, Switzerland: World Health Organization. https://www.who.int/emergencies/diseases/novel-coronavirus-2019/situation-reports [Accessed April 26, 2020] 
Table 1. Descriptive statistics for the individual items in each wave

\begin{tabular}{|c|c|c|c|c|c|c|c|}
\hline \multirow[b]{2}{*}{ COVID-19 items } & & \multicolumn{2}{|c|}{$\begin{array}{c}\text { Wave1 } \\
(n=1,248)\end{array}$} & \multicolumn{2}{|c|}{$\begin{array}{c}\text { Wave2 } \\
(n=1,076)\end{array}$} & \multicolumn{2}{|c|}{$\begin{array}{c}\text { Wave3 } \\
(n=1,004)\end{array}$} \\
\hline & & Mean & $S D$ & Mean & $S D$ & Mean & $S D$ \\
\hline & 6.22 & 1.08 & 6.33 & 1.03 & 6.47 & 0.95 \\
\hline & Estimation of infection probability ${ }^{\mathrm{b}}$ & \multicolumn{2}{|c|}{-} & \multicolumn{2}{|c|}{38.66} & \multicolumn{2}{|c|}{45.06} \\
\hline \multicolumn{8}{|l|}{ Risk perception ${ }^{\mathrm{c}}$} \\
\hline \multirow[t]{2}{*}{ COVID-19 } & I & 5.52 & 1.20 & 5.45 & 1.16 & 5.41 & 1.19 \\
\hline & II & 5.25 & 1.24 & 5.44 & 1.14 & 5.51 & 1.15 \\
\hline \multirow[t]{2}{*}{ Nuclear accidents } & I & 5.09 & 1.42 & 5.06 & 1.36 & 5.04 & 1.39 \\
\hline & II & 4.70 & 1.38 & 4.69 & 1.34 & 4.80 & 1.34 \\
\hline \multirow[t]{2}{*}{ AIDS } & I & 4.30 & 1.42 & - & - & - & - \\
\hline & II & 3.61 & 1.38 & - & - & - & - \\
\hline Influenza & I & - & - & 4.68 & 1.19 & 4.58 & 1.18 \\
\hline & II & - & - & 4.31 & 1.16 & 4.26 & 1.17 \\
\hline Preventive behaviors ${ }^{\mathrm{d}}$ & & & & & & & \\
\hline & Prior & $\mathrm{Wa}$ & & & & & \\
\hline Hand wash & 88.84 & 93 & & & & & \\
\hline Gargle & 62.42 & 70 & & & & & \\
\hline Hand sanitizer & 28.51 & 42 & & & & & \\
\hline Mask & 51.67 & 69 & & & & & \\
\hline Sleep & 72.27 & 74 & & & & & \\
\hline Refrain from public transpor & 27.44 & 44 & & & & & \\
\hline Refrain from public places & 20.52 & 50 & & & & & \\
\hline $\begin{array}{l}\text { Refrain from sightseeing } \\
\text { spots (by foreigners) }\end{array}$ & 22.43 & 60 & & & & & \\
\hline $\begin{array}{l}\text { Refrain from sightseeing } \\
\text { spots (by Chinese) }\end{array}$ & 21.14 & 65 & & & & & \\
\hline $\begin{array}{l}\text { Refraining from leaving } \\
\text { home }\end{array}$ & 13.97 & 33 & & & & & \\
\hline Other & 6.60 & 11 & & & & & \\
\hline & & & & $a n$ & & & \\
\hline The number of behaviors & 4.12 & 6. & & & & & \\
\hline Individual items & & Mean & $S D$ & Mean & $S D$ & Mean & $S D$ \\
\hline Infection-avoidance ${ }^{\mathrm{e}}$ & & 4.85 & 1.21 & 4.91 & 1.21 & 4.99 & 1.25 \\
\hline Frequency of contacting with & greioners & not & & som & what & extr & nely \\
\hline & & 63. & & & & & \\
\hline Presence of acquaintances & Foreigners & 21.71 & & - & - & - & - \\
\hline and friends ${ }^{f}$ & Chinese & 7.45 & & - & - & - & - \\
\hline Exclusionary attitudes & & Mean & $S D$ & Mean & $S D$ & Mean & $S D$ \\
\hline Acceptance attitude toward ${ }^{\mathrm{g}}$ & Foreigner & 4.62 & 1.42 & 4.59 & 1.45 & 4.46 & 1.48 \\
\hline & Chinese & 3.64 & 1.64 & 3.61 & 1.66 & 3.60 & 1.68 \\
\hline Foreigner-avoidance attitude & & 2.77 & 1.64 & 2.82 & 1.64 & 2.89 & 1.68 \\
\hline Impression $^{\mathrm{i}}$ & & & & & & & \\
\hline & IV & 2.75 & 1.49 & 2.90 & 1.43 & 2.98 & 1.47 \\
\hline Foreioners & V & 3.31 & 1.55 & 3.58 & 1.54 & 3.63 & 1.52 \\
\hline Forelgners & VI & 3.61 & 1.17 & 3.58 & 1.13 & 3.52 & 1.11 \\
\hline & VII & 4.31 & 1.62 & 4.31 & 1.52 & 4.20 & 1.47 \\
\hline & IV & 4.15 & 1.72 & 4.14 & 1.73 & 4.15 & 1.78 \\
\hline 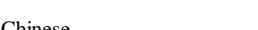 & V & 4.36 & 1.71 & 4.36 & 1.71 & 4.39 & 1.75 \\
\hline Cnmese & VI & 2.55 & 1.26 & 2.58 & 1.26 & 2.63 & 1.27 \\
\hline & VII & 3.31 & 1.64 & 3.50 & 1.64 & 3.47 & 1.62 \\
\hline & IV & 2.66 & 1.31 & 2.74 & 1.30 & 2.91 & 1.33 \\
\hline American & $\mathrm{V}$ & 3.34 & 1.43 & 3.44 & 1.44 & 3.50 & 1.47 \\
\hline American & VI & 3.91 & 1.08 & 3.92 & 1.07 & 3.77 & 1.09 \\
\hline & VII & 4.26 & 1.51 & 4.25 & 1.42 & 4.09 & 1.42 \\
\hline & IV & 3.22 & 1.40 & 3.16 & 1.35 & 3.27 & 1.42 \\
\hline Jananese & $\mathrm{V}$ & 3.18 & 1.41 & 3.14 & 1.38 & 3.38 & 1.46 \\
\hline Japanese & VI & 4.48 & 1.23 & 4.53 & 1.24 & 4.31 & 1.22 \\
\hline & VII & 4.28 & 1.43 & 4.33 & 1.41 & 4.28 & 1.36 \\
\hline & IV & - & - & 2.12 & 1.16 & 2.16 & 1.18 \\
\hline Friends & $\mathrm{V}$ & - & - & 1.93 & 1.11 & 2.03 & 1.19 \\
\hline & VI & - & - & 5.71 & 1.21 & 5.64 & 1.17 \\
\hline & VII & - & - & 5.39 & 1.24 & 5.29 & 1.22 \\
\hline & IV & - & - & 2.88 & 1.38 & 3.01 & 1.34 \\
\hline Unfamiliar & $\mathrm{V}$ & - & - & 3.06 & 1.34 & 3.26 & 1.36 \\
\hline Unfamiliar & VI & - & - & 3.20 & 1.18 & 3.24 & 1.15 \\
\hline & VII & - & - & 3.00 & 1.37 & 3.03 & 1.32 \\
\hline $\begin{array}{l}\text { Notes: Variables a, c, e, g, h, and i } \\
\text { was measured on a \% scale. } \\
\text { 'dreadful' and II = 'unknown' } \\
\text { from } 1 \text { ('not at all') to } 3 \text { ('extr } \\
\text { IV = 'disgusting', V = 'dreadf }\end{array}$ & $\begin{array}{l}\text { ere measured } \\
\text { ne roman num } \\
\text { Variables }{ }^{\mathrm{d}, \mathrm{f}} \text { at } \\
\text { nely'). The ro }\end{array}$ & $\begin{array}{l}\text { a scale } \\
\text { als of }\end{array}$ & $\begin{array}{l}\mathrm{m} 1{ }^{\mathrm{m}} \\
\mathrm{bble}^{\mathrm{c}}\end{array}$ & $\begin{array}{l}\text { ot at a } \\
\text { dicate } \\
\text { Variab } \\
\text { riable } \\
{ }^{i}\end{array}$ & $\begin{array}{l}\text { o } 7 \text { ('st } \\
\text { followi } \\
\text { was me } \\
\text { icate th }\end{array}$ & $\begin{array}{l}\text { ngly'). } \\
\text { subsca } \\
\text { sured on } \\
\text { followin }\end{array}$ & $\begin{array}{l}\text { iriable } \\
\text { s: } \mathrm{I}= \\
\text { scale } \\
\text { items: }\end{array}$ \\
\hline
\end{tabular}


Table 2. A generalized linear mixed model for the number of infection-preventive actions

\begin{tabular}{|c|c|c|c|c|c|c|c|c|c|c|c|c|}
\hline & \multicolumn{4}{|c|}{ vs. Prior } & \multicolumn{4}{|c|}{ vs. Wave1 } & \multicolumn{4}{|c|}{ vs. Wave2 } \\
\hline & $B$ & S.E. & $Z$ & & $B$ & S.E. & $Z$ & & $B$ & S.E. & $Z$ & \\
\hline (Intercept) & 1.07 & 0.07 & 15.52 & $* * *$ & 1.07 & 0.07 & 15.53 & ***** & 1.07 & 0.07 & 15.52 & *** \\
\hline Sex (vs. female) & -0.13 & 0.02 & -5.97 & **** & -0.13 & 0.02 & -5.97 & **** & -0.13 & 0.02 & -5.97 & $* * *$ \\
\hline Age & 0.00 & 0.00 & -1.77 & $\dagger$ & 0.00 & 0.00 & -1.77 & $\dagger$ & 0.00 & 0.00 & -1.77 & $\dagger$ \\
\hline Interest in COVID-19 & 0.10 & 0.01 & 10.95 & **** & 0.10 & 0.01 & 10.95 & $* * *$ & 0.10 & 0.01 & 10.96 & $* * *$ \\
\hline Infection-avoidance & 0.08 & 0.01 & 8.99 & **** & 0.08 & 0.01 & 9.00 & $* * *$ & 0.08 & 0.01 & 8.97 & $* * *$ \\
\hline Prior & - & - & - & & -0.39 & 0.02 & -20.13 & $* * *$ & -0.14 & 0.02 & -7.00 & $* * *$ \\
\hline Wave1 & 0.39 & 0.02 & 20.15 & **** & - & - & - & & 0.24 & 0.02 & 13.04 & $* * *$ \\
\hline Wave2 & 0.15 & 0.02 & 7.08 & **** & -0.24 & 0.02 & -13.01 & *** & - & - & - & \\
\hline Wave3 & 0.26 & 0.02 & 12.72 & *** & -0.13 & 0.02 & -6.91 & $* * *$ & 0.12 & 0.02 & 5.92 & $* * *$ \\
\hline \multicolumn{13}{|l|}{ Infection-avoidance: } \\
\hline Prior & - & - & - & & 0.01 & 0.02 & 0.34 & & -0.02 & 0.02 & -0.93 & \\
\hline Wave1 & -0.01 & 0.02 & -0.35 & & - & - & - & & -0.02 & 0.02 & -1.38 & \\
\hline Wave2 & 0.02 & 0.02 & 0.94 & & 0.02 & 0.02 & 1.39 & & - & - & - & \\
\hline Wave3 & 0.00 & 0.02 & -0.23 & & 0.00 & 0.02 & 0.10 & & -0.02 & 0.02 & -1.22 & \\
\hline
\end{tabular}

Table 3. A generalized linear model for the number of infection-preventive actions before the

$$
\text { spread of infection }
$$

\begin{tabular}{lccc}
\hline & $B$ & S.E. & $t$ \\
\hline (Intercept) & 2.77 & 0.44 & $6.24^{* * *}$ \\
Sex (vs. female) & -0.26 & 0.13 & $-2.05^{*}$ \\
Age & -0.01 & 0.01 & -1.41 \\
Interest in COVID-19 & 0.09 & 0.06 & 1.54 \\
Infection-avoidance & 0.34 & 0.05 & $6.81^{* * *}$ \\
${ }^{* * * *} p<.001 ;{ }^{*} p<.05$ & & &
\end{tabular}


Table 4. A general linear mixed model of acceptance attitudes toward (a) foreigners in general, (b) the Chinese, and (c) avoidance attitudes toward foreigners

\begin{tabular}{|c|c|c|c|c|c|c|c|c|}
\hline & \multicolumn{4}{|c|}{ vs. Wave1 } & \multicolumn{4}{|c|}{ vs. Wave 2} \\
\hline & $B$ & S.E. & $t$ & & $B$ & S.E. & $t$ & \\
\hline \multicolumn{8}{|l|}{ Model a } & $* * *$ \\
\hline Sex (vs. female) & -0.12 & 0.08 & -1.47 & & -0.12 & 0.08 & -1.47 & \\
\hline Age & -0.02 & 0.00 & -3.64 & ${ }^{* * * *}$ & -0.02 & 0.00 & -3.64 & *** \\
\hline Interest in COVID-19 & -0.01 & 0.02 & -0.47 & & -0.01 & 0.02 & -0.47 & \\
\hline Infection-avoidance & -0.17 & 0.03 & -5.42 & ${ }^{* * * *}$ & -0.17 & 0.03 & -5.42 & ${ }^{* * *}$ \\
\hline Contact with foreigners & 0.17 & 0.06 & 2.69 & ${ }^{* *}$ & 0.17 & 0.06 & 2.69 & $* *$ \\
\hline Wave1 & - & - & - & & 0.02 & 0.03 & 0.61 & \\
\hline Wave2 & -0.02 & 0.03 & -0.61 & & - & - & - & \\
\hline Wave3 & -0.14 & 0.03 & -4.49 & ${ }^{* * * *}$ & -0.12 & 0.03 & -3.92 & *** \\
\hline \multicolumn{9}{|l|}{ Infection-avoidance: } \\
\hline Wave1 & - & - & - & & 0.01 & 0.02 & 0.57 & \\
\hline Wave2 & -0.01 & 0.02 & -0.57 & & - & - & - & \\
\hline Wave3 & -0.04 & 0.03 & -1.53 & & -0.02 & 0.03 & -0.98 & \\
\hline \multicolumn{9}{|c|}{ Contact with foreigners: } \\
\hline Wave1 & - & - & - & & -0.03 & 0.05 & -0.65 & \\
\hline Wave2 & 0.03 & 0.05 & 0.65 & & - & - & - & \\
\hline Wave3 & 0.04 & 0.05 & 0.78 & & 0.01 & 0.05 & 0.15 & \\
\hline \multicolumn{9}{|l|}{ Model b } \\
\hline Sex (vs. female) & $\begin{array}{l}4.33 \\
0.18\end{array}$ & $\begin{array}{l}0.23 \\
0.10\end{array}$ & $\begin{array}{r}18.19 \\
1.87\end{array}$ & $\dagger$ & $\begin{array}{l}4.33 \\
0.18\end{array}$ & $\begin{array}{l}0.23 \\
0.10\end{array}$ & $\begin{array}{r}18.19 \\
1.87\end{array}$ & $\dagger$ \\
\hline Age & -0.01 & 0.00 & -1.43 & & -0.01 & 0.00 & -1.43 & \\
\hline Interest in COVID-19 & -0.08 & 0.02 & -3.53 & *** & -0.08 & 0.02 & -3.53 & *** \\
\hline Infection-avoidance & -0.17 & 0.04 & -4.61 & ${ }^{* * *}$ & -0.17 & 0.04 & -4.61 & *** \\
\hline Contact with foreigners & 0.14 & 0.08 & 1.90 & + & 0.14 & 0.08 & 1.90 & $\dagger$ \\
\hline Wave1 & - & - & - & & 0.01 & 0.03 & 0.42 & \\
\hline Wave2 & -0.01 & 0.03 & -0.42 & & - & - & - & \\
\hline Wave3 & -0.02 & 0.03 & -0.59 & & -0.01 & 0.03 & -0.18 & \\
\hline \multicolumn{9}{|l|}{ Infection-avoidance: } \\
\hline Wave 1 & - & - & - & & 0.04 & 0.03 & 1.36 & \\
\hline Wave2 & -0.04 & 0.03 & -1.36 & & - & - & - & \\
\hline Wave3 & -0.02 & 0.03 & -0.80 & & 0.01 & 0.03 & 0.51 & \\
\hline \multicolumn{9}{|l|}{ Contact with foreigners: } \\
\hline Wave1 & - & - & - & & -0.04 & 0.05 & -0.81 & \\
\hline Wave2 & 0.04 & 0.05 & 0.81 & & - & - & - & \\
\hline Wave3 & 0.11 & 0.06 & 1.93 & + & 0.06 & 0.06 & 1.14 & \\
\hline \multicolumn{9}{|l|}{ Model c } \\
\hline (Intercept) & 2.31 & 0.23 & 10.11 & ${ }^{* * *}$ & 2.31 & 0.23 & 10.11 & *** \\
\hline Sex (vs. female) & 0.39 & 0.09 & 4.11 & ${ }^{* * * *}$ & 0.39 & 0.09 & 4.11 & ${ }^{* * * *}$ \\
\hline Age & 0.01 & 0.00 & 1.47 & & 0.01 & 0.00 & 1.47 & \\
\hline Interest in COVID-19 & 0.02 & 0.02 & 0.90 & & 0.02 & 0.02 & 0.90 & \\
\hline Infection-avoidance & 0.27 & 0.04 & 7.17 & ${ }^{* * *}$ & 0.27 & 0.04 & 7.17 & *** \\
\hline Contact with foreigners & -0.18 & 0.07 & -2.40 & * & -0.18 & 0.07 & -2.40 & $*$ \\
\hline Wave1 & - & - & - & & -0.04 & 0.03 & -1.19 & \\
\hline Wave2 & 0.04 & 0.03 & 1.19 & & - & - & - & \\
\hline Wave3 & 0.08 & 0.03 & 2.41 & ${ }^{*}$ & 0.04 & 0.03 & 1.26 & * \\
\hline \multicolumn{9}{|l|}{ Infection-avoidance: } \\
\hline Wave1 & - & - & - & & -0.01 & 0.03 & -0.31 & \\
\hline Wave2 & 0.01 & 0.03 & 0.31 & & - & - & - & \\
\hline Wave3 & 0.05 & 0.03 & 1.88 & $\dagger$ & 0.04 & 0.03 & 1.58 & \\
\hline \multicolumn{9}{|l|}{ Contact with foreigners: } \\
\hline Wave1 & - & - & - & & -0.01 & 0.05 & -0.18 & \\
\hline Wave2 & 0.01 & 0.05 & 0.18 & & - & - & - & \\
\hline Wave3 & 0.03 & 0.06 & 0.54 & & 0.02 & 0.06 & 0.37 & \\
\hline
\end{tabular}


COVID-19 and Exclusionary Attitudes

Table 5. A general linear mixed model of impressions of unfamiliar people

\begin{tabular}{|c|c|c|c|c|c|c|c|c|}
\hline & \multicolumn{4}{|c|}{ negative } & \multicolumn{4}{|c|}{ positive } \\
\hline & \multicolumn{8}{|c|}{ vs. Wave2 } \\
\hline & $B$ & S.E. & $t$ & & $B$ & S.E. & $t$ & \\
\hline (Intercept) & 3.27 & 0.22 & 15.05 & $* * *$ & 2.37 & 0.19 & 12.65 & **** \\
\hline Sex (vs. female) & 0.08 & 0.07 & 1.06 & & 0.04 & 0.06 & 0.72 & \\
\hline Age & 0.00 & 0.00 & -0.20 & & 0.01 & 0.00 & 4.44 & **** \\
\hline Interest in COVID-19 & -0.04 & 0.03 & -1.38 & & 0.03 & 0.02 & 1.37 & \\
\hline Infection-avoidance & 0.15 & 0.03 & 5.12 & $* * *$ & -0.04 & 0.02 & -1.48 & \\
\hline Contact with foreigners & 0.09 & 0.06 & 1.58 & & 0.04 & 0.05 & 0.77 & \\
\hline Wave3 & 0.16 & 0.03 & 4.76 & $* * *$ & 0.02 & 0.03 & 0.62 & \\
\hline Infection-avoidance: Wave3 & -0.07 & 0.03 & -2.43 & $*$ & -0.01 & 0.03 & -0.29 & \\
\hline Contact with foreigners: Wave3 & -0.01 & 0.06 & -0.16 & & -0.06 & 0.05 & -1.11 & \\
\hline
\end{tabular}

